\title{
Bon Voyage!
}

Dear Reader,

If you research into the emissions from shipping, you will find that there is a lot of information available, but it is often contradictory. For example, some sources claim that the entire shipping industry is responsible for around $15 \%$ of global nitrogen oxide emissions and $13 \%$ of sulfur dioxide emissions. I have no way of telling whether these figures are correct, but during the course of many conversations with friends I have found that the subject of emissions, and in particular emissions from cruise liners, is increasingly in the forefront of people's minds. The passengers on these ships want to enjoy their vacation, because it is supposed to be the high point of their year, without having to worry about the environmental footprint of the cruise. No one wants to have to justify to friends, relatives, and neighbors the fact that they have chosen to spend their holiday at sea instead of in a hotel on land. This is an emotional issue and it is difficult for engineers to counteract the arguments with facts and figures, in particular on social media. However, the Storting, the Norwegian parliament, has now dropped a legislative bombshell. In resolution 672 it has ruled that from 2026 onward only zero-emission ships can enter the waters of the Geirangerfjord, the country's most famous fjord, which has been a UNESCO World Heritage Site since 2005. Of course, this is just the first small-scale measure, but I fear that it is only a question of time before other countries introduce similar regional bans. More and more shipping companies are opting for new engine technologies, improved exhaust emission control systems, and alternative fuels, such as Liquefied Natural Gas (LNG), before they are forced to take these steps by new legislation. In my view that is the right way to overcome public reservations before the discussions get out of hand.
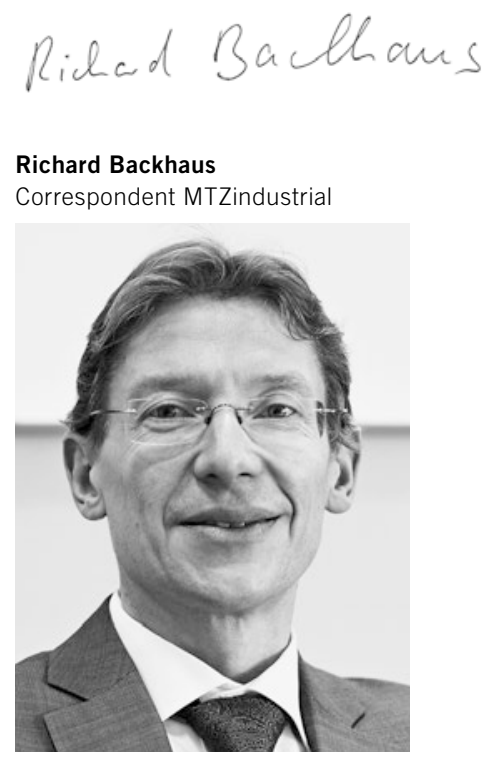